\title{
Eksplorasi Etnomatematika pada Pembuatan Motif Batik Khas Kabupaten Majalengka
}

\author{
Sudianto $^{1}$, Erik Santoso ${ }^{2}$ \\ ${ }^{1,2}$ Program Studi Pendidikan Matematika, Universitas Majalengka \\ Jl. Raya K H Abdul Halim No.103, Majalengka \\ sudianto@unma.ac.id
}

\begin{abstract}
Batik is an Indonesian culture that is characteristic of Indonesia which has been recognized internationally. The culture of making batik or making batik motifs is closely related to certain patterns. Philosophically, some batik motifs when analyzed are related to mathematical concepts. This study uses a qualitative method with an ethnographic approach. This study aims to describe an in-depth study of batik motifs and their relation to mathematical concepts. The instruments and data collection techniques used were observation, interview guidelines and documentation. Meanwhile, the subject of this research is batik craftsmen in Majalengka Regency. Based on the results of the study, it was found that culture and mathematics have a relationship with each other, one of which is the culture of batik. In the typical Majalengka batik motif, the Rengginang batik motif has a relationship with the mathematical concept of congruence in the field. Meanwhile, the Kota Angin batik motif has a relationship with the concept of translation, then the Kopi and Edelweis motifs have a relationship with the concept of reflection. In addition, the Gunungwangi Coffee motif has a relationship with rotation and the Gedong Ginju motif has a relationship with the concept of dilation.
\end{abstract}

Keywords: Ethnomathematics Exploration, Typical Batik Motifs of Majalengka

\begin{abstract}
Abstrak
Batik merupakan budaya Indonesia yang menjadi ciri khas Indonesia yang sudah diakui secara internasional. Budaya membatik atau membuat motif batik erat kaitannya dengan pola-pola tertentu. Secara filosofis beberapa motif batik jika dianalisis ada keterkaitannya dengan konsep matematis. Penelitian ini menggunakan metode kualitatif dengan pendekatan etnografi. Penelitian ini bertujuan untuk mendeskripsikan kajian yang mendalam mengenai motif batik dan kaitannya dengan konsep matematis. Teknik pengumpulan data yang digunakan yaitu observasi, pedoman wawancara dan dokumentasi. Sementara untuk subjek penelitian ini adalah pengerajin batik yang berada di Kabupaten Majalengka. Berdasarkan hasil penelitian diperoleh bahwa budaya dan matematika mempunyai keterkaitan satu sama lain, salah-satunya yaitu pada budaya membatik. Pada motif batik khas Majalengka yaitu motif batik Rengginang memiliki keterkaitan dengan konsep matematika yaitu Kongruen pada bidang. Sementara itu pada motif batik Kota Angin memiliki keterkaitan dengan konsep translasi, kemudian pada motif Kopi dan Edelweis memiliki keterkaitan dengan konsep pencerminan. Selain itu pada motif Kopi Gunungwangi memiliki keterkaitan dengan rotasi dan motif Gedong Ginju memiliki keterkaitan dengan konsep dilatasi.
\end{abstract}

Keywords: Eksplorasi Etnomatematika, Motif Batik Khas Kabupaten Majalengka

Copyright (c) 2021 Sudianto, Erik Santoso

$\triangle$ Corresponding author: Sudianto

Email Address: sudianto@unma.ac.id (Jl. Raya K H Abdul Halim No.103, Majalengka)

Received 30 July 2021, Accepted 28 August 2021, Published 10 September 2021

\section{PENDAHULUAN}

Budaya merupakan buah pikir dari seseorang yang erat kaitannya dengan keindahan. This sense of culture is more closely related to aesthetics than to social science (Spencer-Oatey, 2012). Bedasarkan pendapat tersebut budaya erat kaitannya nilai estetika atau keindahan. Indonesia terkenal memiliki budaya yang sangat beragam. Hal ini didasari karena Indonesia merupakan salah satu negara kepulauan di dunia. Salah satu budaya warisan asli Indonesia adalah batik. Tanggal 2 Oktober menjadi hari batik nasional stelah ditetapkan oleh UNESCO sebagai Masterpieces of the Oral and Intangibel Heritage of Humanity pada tanggal 2 Oktober 2009. 
Kegiatan manusia adalah kegiatan matematika juga. Hal ini seperti yang diungkapkan 'mathematics as a human activity' (Shanty, 2016) (Prahmana, Zulkardi, \& Hartono, 2012). Pendapat tersebut mengisyaratkan bahwa matematika selalu berhubungan dengan aktivitas manusia. Termasuk didalamnya adalah aktivitas berbudaya. Budaya dalam matematika di kenal dengan etnomatemtaika. Ethnomathematics is a research program that focuses on the relationships between mathematics and culture (Albanese \& Perales, 2015). Kemudian pendapat tersebut di perkuat dengan pendapat bahwa etnomatematika didefiniskan sebagai antropologi budaya dari matematika dan pendidikan matematika sehingga terjadinya sosialisasi budaya (Arwanto, 2017)(Zayyadi, 2017). Berdasarkan pendapat tersebut bahwa ada beberapa budaya yang dilakukan oleh masyarakat yang erat kaitannya dengan matematika.

Sejarah etnomatematika berawal dari penelitian oleh D'Ambrosio."Mathematics is practiced among cultural groups identified as a national community, ethnic, labor groups, children of a certain age group and professional class (D'Ambrosio, 1985). Bahwa matematika praktis banyak dijumpai dari budaya dari suatu kelompok tertentu. Hal inilah melahirkan bahwa budaya tidak bisa dilepaskan dari matematika.

Batik khas Majalengka memiliki keunikan dengan batik yang lainnya. Salah seorang seniman yang mempopulerkan batik Majalengka adalah Herry Suherseno yang merupakan seniman bordir. Motif Batik Majalengka yaitu, Simbar Kencana, Nyi Rambut Kasih, Kota Angin, Gedong Gincu, dan Lauk Ngibing. Kesemua corak itu merupakan kekhasan dan produk asli Majalengka (Batik, 2018).

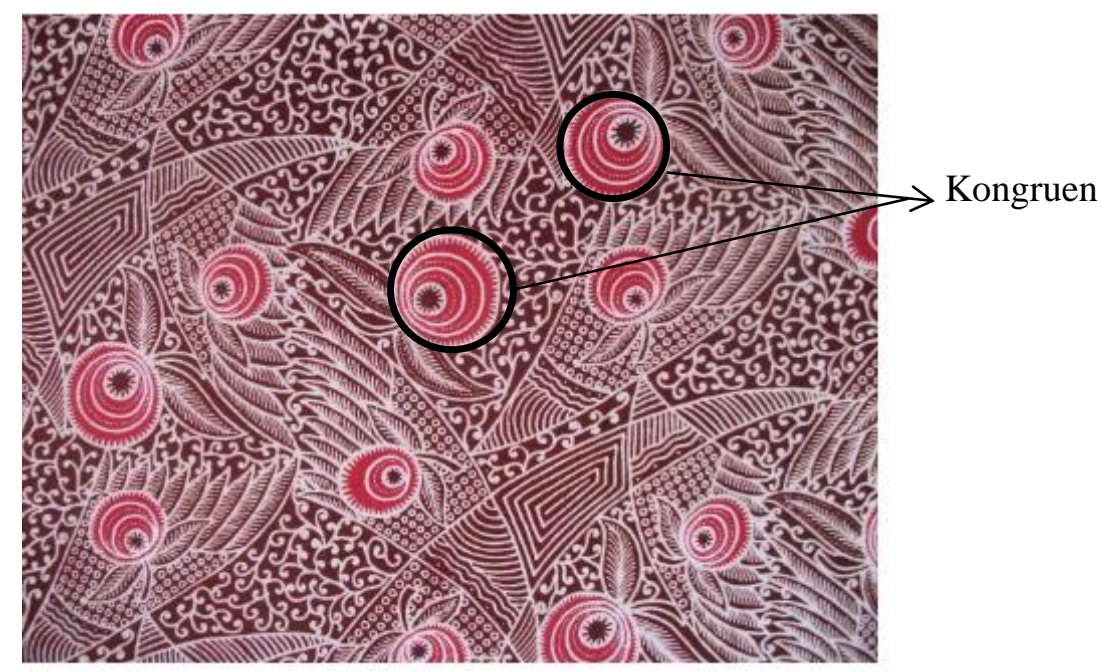

Gambar 1. Motif Batik Gedong Gincu

Motif batik gedong gincu merupakan motif batik khas Majalengka yang terimajinasi dari buah khas Majalengka yaitu Buah Gedung Gincu. Apabila kita analisis motif batik ini maka ada beberapa hal yang bisa kita hubungkan dengan konsep matematika. Contoh sederhan adalah gambar buah yang berwarna merah memiliki keongruenan dengan buah yang lain sedangkan dengan yang besarnya memiliki hubungan dengan konsep kesebangunan. 
Aktivitas membuat motif batik seringkali tidak disadari ada kaitannya dengan konsep matematika. Hal ini dikarenakan para seniman lebih melihat dari unsur keindahannya saja. Padahal jika ditinjau lebih dalam lagi banyak sekali motif batik yang berkaitan dengan konsep matematika. Oleh karena itu, etnomatematika menjadi berkembang dengan pesat dan adakalanya dihubungkan dengan pembelajaran matematika di kelas. Hal ini diperkuat dengan hasil penelitian yang menyebutkan bahwa "Etnomatematika mampu memberikan kompetensi afektif yang berupa terciptanya rasa menghargai, nasionalisme dan kebanggaan atas peninggalan tradisi, seni dan kebudayaan bangsa (Richardo, 2017).

Rasa kebanggaan yang dimaksud adalah rasa budaya suatu daerah yang merupakan integrasi dari budaya Nasional. Melalui penelitian ini, peneliti berharap bahwa siswa yang berada di Kabupaten Majalengka memiliki kecintaan terhadap matematika, dan melalui penelitian siswa menjadi lebih cinta terhadap budaya yang ada di Majalengka khsusnya motif batik Majalengka. Bagi guru melalui riset ini ketika melakukan pembelajaran pada konsep konsep tertentu seperti konsep kesebangunan dan kekongruenan dapat memberi contoh mengenai motif batik matematika.

\section{METODE}

Jenis penelitian ini merupakan jenis penelitian kualitatif dengan pendekatan etnografi. Sementara untuk subjek dalam penelitian ini adalah pembatik yang berada di wilayah Kabupaten Majalengka yaitu Batik Miranti yang berada di jalan Emen Slamet No. 6 Majalengka. Instrumen dan teknik pengumpulan data yang digunakan dalam melaksanakan penelitian ini terdari dari tiga macam yaitu: observasi, pedoman wawancara dan dokumentasi. Observasi digunakan untuk melihat aktivitas kegiatan membatik di Kabupaten Majalengka, wawancara digunakan untuk memeperolah data mengenai pembuatan motif batik kepada para pembatik dan dokumentasi digunakan untuk mendokumentasikan pola motif batik yang dibuat. Adapun teknik analisis dalam penelitian ini yaitu dimulai dari pengumpulan data, mereduksi data, menyajikan data, dan membuat kesimpulan. Analisis data dilakukan sebelum memasuki lapangan, selama di lapangan, dan setelah selesai di lapangan.

\section{HASIL DAN DISKUSI}

Majalengka memiliki beberapa motif batik ciri khas diantaranya yaitu Simbar Kencana, Nyi Rambut Kasih, Kota Angin, Gedong Gincu, dan Lauk Ngibing. Kesemua corak itu merupakan kekhasan dan produk asli Majalengka. Selain motif yang disebutkan diatas ada beberapa motif khas majalengka yang lainnya diantaranya yaitu motif batik Rengginang, Kopi dan Bunga Edelweis, Motif Kopi Gunungwangi dan yang lainnya. Berdasarkan kunjangan peneliti pada pengerajin Batik Miranti ada beberapa motif batik yang diambil untuk dilakukan analisis yaitu sebagai berikut:

\section{Motif Batik Rengginang}

Motif batik rengginang merupakan salahsatu motif batik khas majalengka yang berasal dari Kecamatan Ligung Kabupaten Majalengka. Dinamakan motif rengginang terinspirasi dari salah satu 
makanan yang ada di Majalengka yang terbuat dari nasi atau beras ketan yang dikeringkan. Adapun untuk gambar motif rengginang adalah sebagai berikut.

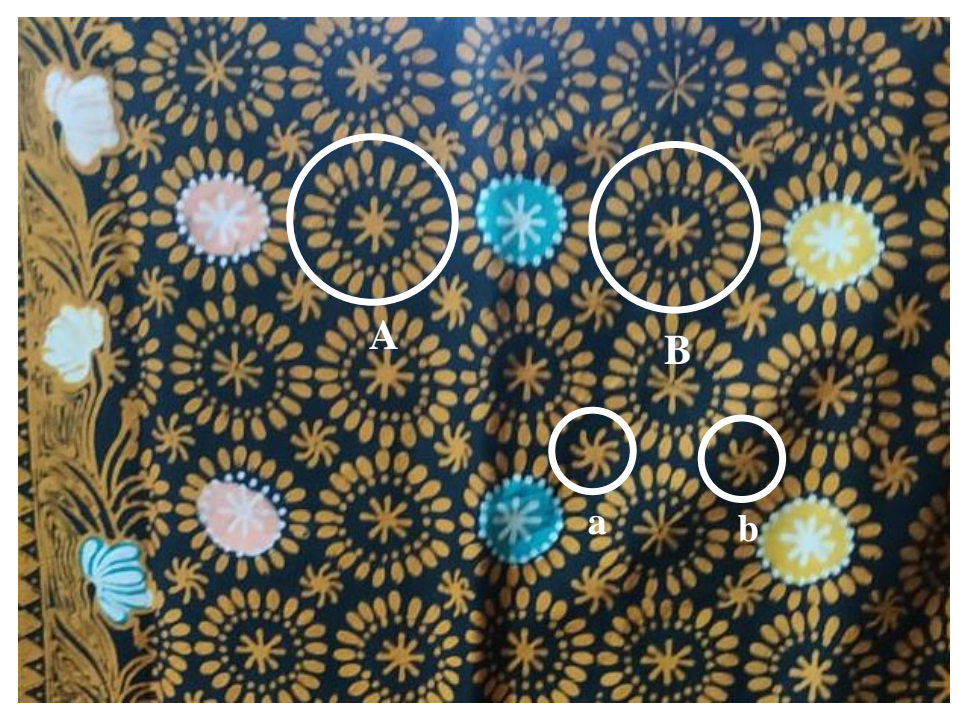

Gambar 2. Motif batik Rengginang

Berdasarkan gambar di atas dapat dilihat bahwa pada motif batik khas majalengka yaitu motif batik Rengginang memiliki keterkaitan dengan konsep kongruen pada bidang. Secara geometri, dua bangun datar atau objek lainnya disebut (saling) kongruen jika keduanya memiliki bentuk dan ukuran yang sama. Dari objek diatas dapat dilihat bahwa titik $A$ kongruen terhadap titik $B$, begitu juga titik $a$ kongruen terhadap titik $b$. Sehingga secara konsep matematika dapat dinyatakan $A \cong B$ dan $a \cong c$

\section{Motif Batik Kota Angin}

Motif batik Kota Angin merupakan batik khas Majalengka yang muncul karena wilayah Majalengka berada di daerah pegunungan gunung Ciremai sehingga memiliki kondisi angin yang cukup besar bertiup sepanjang tahun. Adapun motif batik Kota Angin dapat dilihat pada Gambar 3 .

Berdasarkan gambar tersebut dapat dilihat bahwa pada motif batik khas majalengka yaitu motif batik Kota Angin memiliki keterkaitan dengan konsep geometri transformasi kelas XI SMA yaitu konsep translasi (pergeseran). Menurut Tampomas (2016) translasi merupakan pemindahan suatu objek atau titik dengan arah dan jarak tertentu. Arah dan jarak tertentu ditentukan oleh suatu vektor atau ruas garis berarah. Dari objek diatas dapat dilihat bahwa titik $P$ (kipas) ditranslasikan kekanan sebesar $a$ satuan, kemudian digeser kembali keatas sebesar $b$ satuan, sehingga menghasilkan bayangan $P$ ' yaitu dengan dengan vektor $T=\left(\begin{array}{l}a \\ b\end{array}\right)$. Secara konsep untuk menentukan translasi bisa meggunakan rumus:

$$
P(x, y) \stackrel{T\left(\begin{array}{l}
a \\
b
\end{array}\right)}{\longrightarrow} P^{\prime}(x+a, y+b)
$$




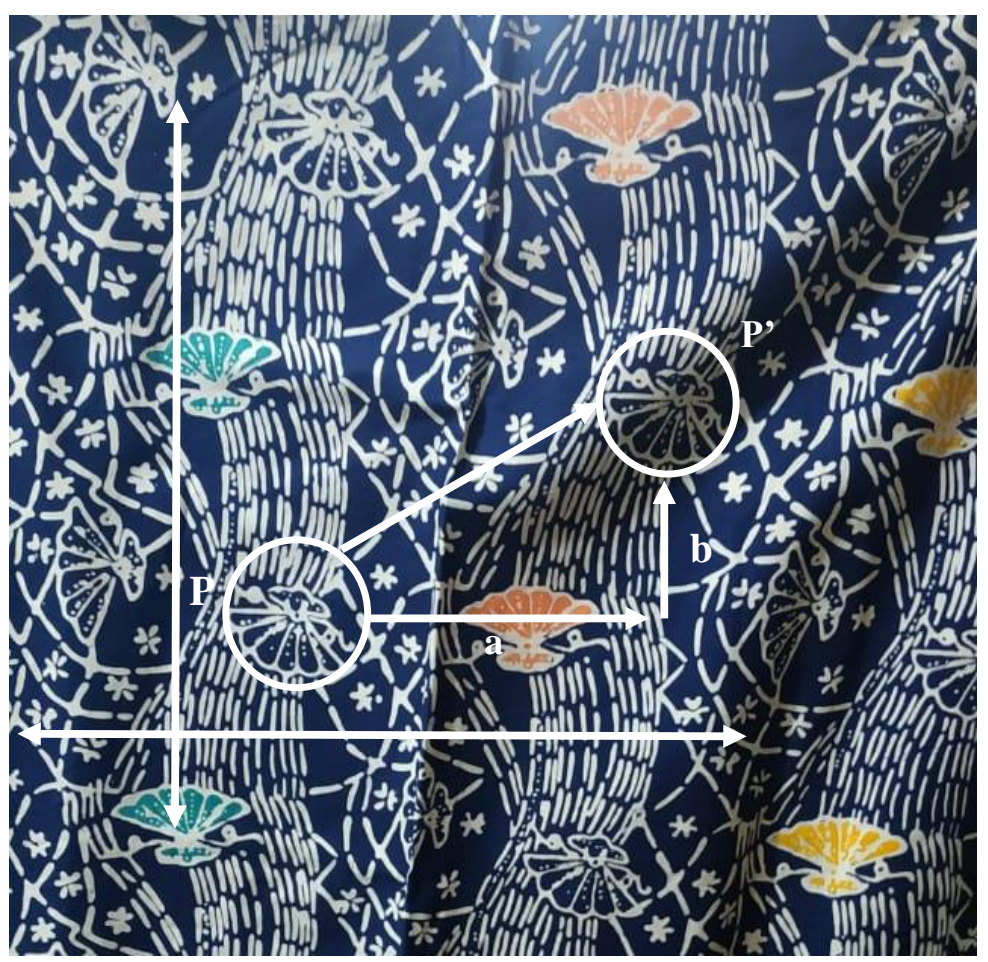

Gambar 3. Motif batik Kota Angin

\section{Motif Batik Kopi dan Edelweis}

Motif batik Kopi dan Edelweis merupakan batik khas Majalengka yang terinspirasi dari biji kopi Gunungwangi kecamatan Argapura dan bunga Edelweis yang tumbuh subur di kawasan Bumi Perkemahan (Buper) Cidewata Majalengka. Bunga Edelweis hanya mampu tumbuh didaerah pegunungan yang memerlukan sinar matahari yang penuh dan dijuluki sebagai bunga abadi. Adapun motif batik Kopi dan bunga Edelweis dapat dilihat pada Gambar 4.

Berdasarkan gambar tersebut dapat dilihat bahwa pada motif batik khas majalengka yaitu motif batik kopi memiliki keterkaitan dengan konsep refleksi (pencerminan). Pencerminan merupakan transformasi setiap titik pada bangun geometri terhadap sebuah garis yang bertindak sebagai sumbu cermin atau sumbu simetri.

Dari objek diatas dapat dilihat bahwa titik $a$ (belah ketupat) dicerminkan terhadap sumbu $y$ sehingga menghasilkan bayangan $a^{\prime}$. Kemudian apabila titik $a^{\prime}$ dicerminkan kembali terhadap sumbu $x$ akan menghasilkan bayangan $a$ ". Secara konsep matematis untuk menentukan bayangan refleksi terhadap sumbu $x: P(x, y) \stackrel{\text { sumbu } x}{\longrightarrow} P^{\prime}(x,-y)$. Sementara refleksi terhadap sumbu y: $P(x, y) \stackrel{\text { sumbu } y}{\longrightarrow} P^{\prime}(-x, y)$ 


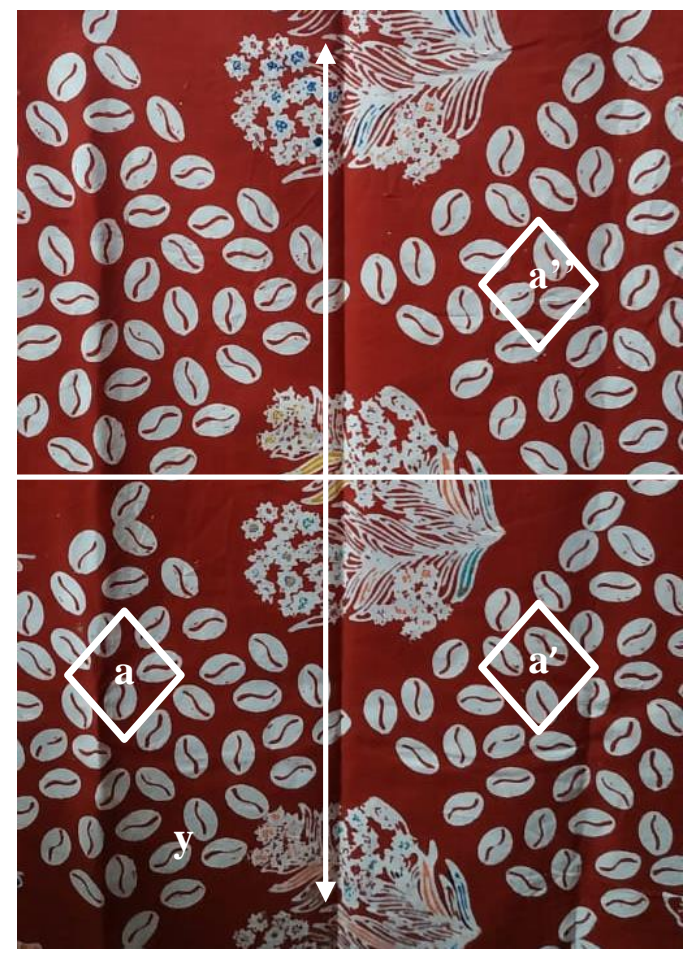

Gambar 4. Motif batik Kopi dan Bunga Edelweis

\section{Motif Batik Kopi Gunungwangi}

Motif batik Kopi Gunungwangi merupakan batik khas Majalengka yang menggambarkan komoditas kopi di desa Gunungwangi kecamatan Argapura Majalengka. Adapun motif Kopi Gunungwangi sebagai berikut:

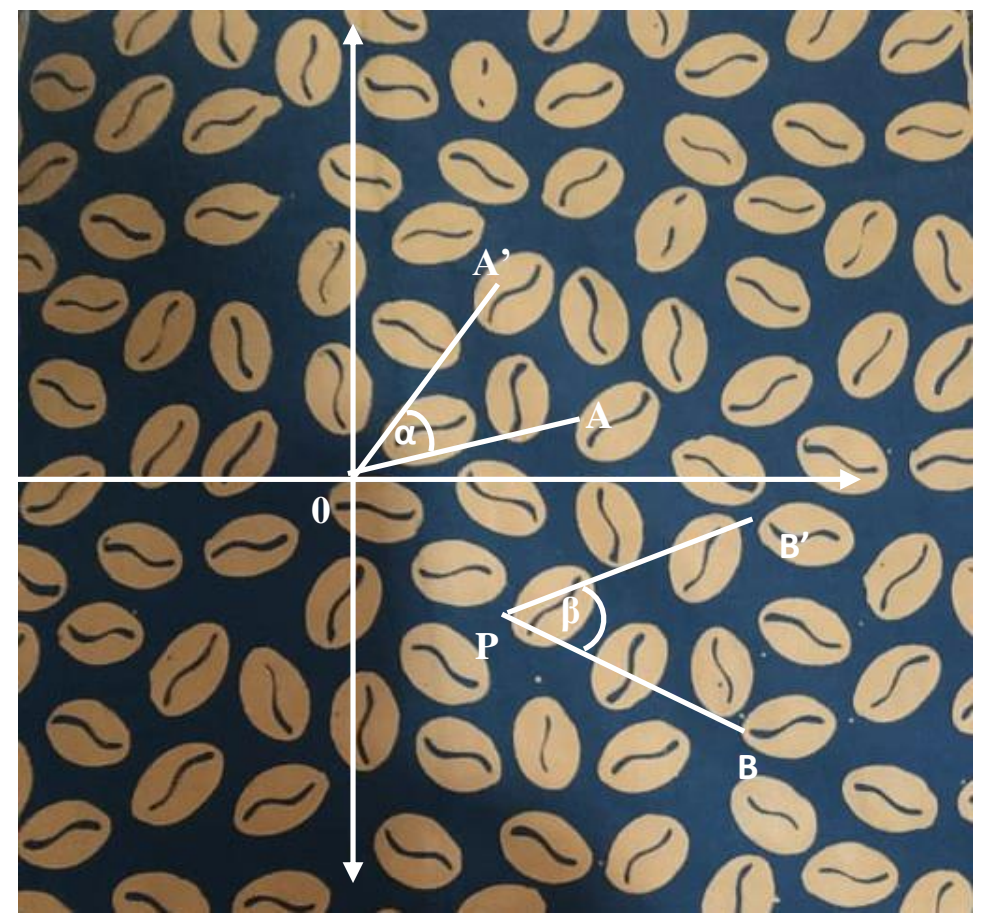

Gambar 5. Motif batik Kopi Gunungwangi 
Berdasarkan gambar diatas dapat dilihat bahwa pada motif batik khas majalengka yaitu motif batik Kopi Sindangwangi memiliki keterkaitan dengan konsep rotasi (perputaran). Menurut Tampomas (2016 : 246) rotasi adalah transformasi yang memindahkan titik-titik dengan cara memutar titik-titik tersebut sejauh $\alpha^{0}$ terhadap suatu titik tertentu. Titik tertentu pada suatu rotasi dinamakan dengan titik pusat. Rotasi bisa dilakukan dengan memutar searah jarum jam maupun berlawanan arah jarum jam.

Dari objek diatas dapat dilihat bahwa titik $A$ (biji kopi) diputar searah jarum jam dengan titik pusat $\mathrm{O}(0,0)$ dengan besar sudut $\alpha$ diperoleh bayangan $A^{\prime}$. Sementara titik $B$ diputar searah arum jam dengan titik pusat $P(a, b)$ dengan besar sudut $\beta$ sehingga diperoleh bayangan $B$ '. Secara konsep matematis untuk menentukan rotasi terhadap titik pusat $\mathrm{O}(0,0)$ dengan besar sudut $\alpha$ dapat dinyatakan:

$$
A^{\prime}=\left(\begin{array}{l}
x^{\prime} \\
y^{\prime}
\end{array}\right)=\left(\begin{array}{cc}
\cos a & -\sin a \\
\sin a & \cos a
\end{array}\right)\left(\begin{array}{l}
x \\
y
\end{array}\right)
$$

Sementara untuk menentukan rotasi pada titik pusat $P(a, b)$ dengan besar sudut $\beta$ dinyatakan dengan:

$$
B^{\prime}=\left(\begin{array}{l}
x^{\prime} \\
y^{\prime}
\end{array}\right)=\left(\begin{array}{cc}
\cos \beta & -\sin \beta \\
\sin \beta & \cos \beta
\end{array}\right)\left(\begin{array}{l}
x-a \\
y-b
\end{array}\right)+\left(\begin{array}{l}
a \\
b
\end{array}\right)
$$

\section{Motif batik Gedong Ginju}

Motif batik Gedong Ginju merupakan batik khas Majalengka yang berasal dari nama buah Mangga "Gedong Ginju" yang merupakan buah khas majalengka. Adapun motif batik Gedong Ginju sebagai berikut:

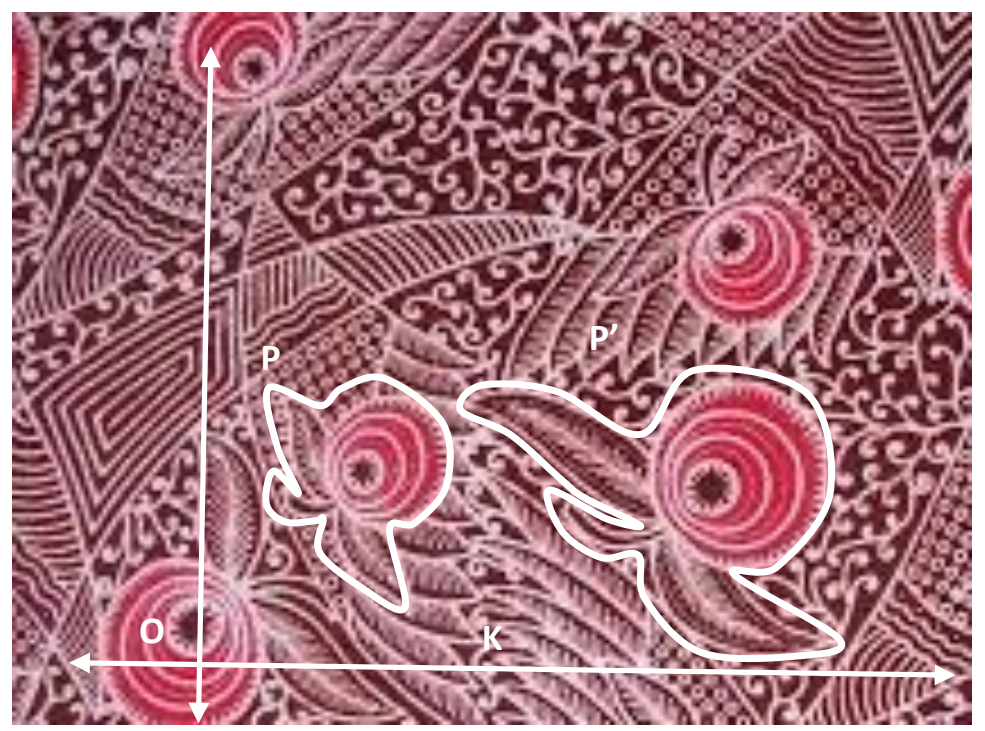

Gambar 6. Motif batik Gedong Ginju

Berdasarkan gambar diatas dapat dilihat bahwa pada motif batik khas majalengka yaitu motif batik gedong ginju memiliki keterkaitan dengan konsep dilatasi (perkalian). Menurut Tampomas (2016) dilatasi merupakan suatu transformasi yang mengubah ukuran (memperbesar/ memperkecil) suatu bangun geometri tetapi tidak mengubah bangun geometri itu. 
Dari objek diatas dapat dilihat bahwa titik $P$ (gedong ginju) didilatasikan dengan titik pusat $\mathrm{O}$ $(0,0)$ dengan faktor skala (perbesaran) $k$, sehingga menghasilkan bayangan $P$ '. Secara konsep untuk menentukan dilatasi pada titik pusat $\mathrm{O}$ dengan faktor skala $k$ bisa meggunakan rumus:

$$
P^{\prime}=\left(\begin{array}{l}
x^{\prime} \\
y^{\prime}
\end{array}\right)=\left(\begin{array}{ll}
k & 0 \\
0 & k
\end{array}\right)\left(\begin{array}{l}
x \\
y
\end{array}\right)
$$

\section{KESIMPULAN}

Berdasarkan hasil penelitian di atas dapat disimpulkan bahwa budaya dan matematika mempunyai keterkaitan satu sama lain, salah-satunya yaitu pada budaya membatik. Pada motif batik khas Majalengka yaitu motif batik Rengginang ternyata memiliki keterkaitan dengan konsep matematika yaitu Kongruen pada bidang. Sementara itu pada motif batik Kota Angin memiliki keterkaitan dengan konsep translasi, kemudian pada motif Kopi dan Edelweis memiliki keterkaitan dengan konsep pencerminan. Selain itu pada motif Kopi Gunungwangi memiliki keterkaitan dengan rotasi dan motif Gedong Ginju memiliki keterkaitan dengan konsep dilatasi.

Penelitian ini diharapkan bisa menjadi referensi bagi siswa, guru maupun masyarakat secara umum. Bagi siswa agar memiliki kecintaan terhadap matematika melalui budaya yang ada di Majalengka khsusnya motif batik Majalengka. Bagi guru melalui riset ini, ketika melakukan pembelajaran pada konsep-konsep tertentu seperti konsep kesebangunan, kekongruenan dan transformasi geometri dapat memberi contoh mengenai motif batik. Bagi masyarakat umum, agar batik khas Majalengka bisa lebih membudaya di kalangan masyarakat dan dikenal luas.

\section{REFERENSI}

Albanese, V., \& Perales Palacios, F. J. (2015). Enculturation with Ethnomathematical Microprojects: From Culture to Mathematics. Journal of Mathematics \& Culture, 9 (February), 1-11.

Arwanto, A. (2017). Eksplorasi Etnomatematika Batik Trusmi Cirebon Untuk Mengungkap Nilai Filosofi Dan Konsep Matematis. Phenomenon: Jurnal Pendidikan MIPA, 7(1), 40-49. https://doi.org/10.21580/phen.2017.7.1.1493

Batik, I. (2018). Sejarah Batik Majalengka. tersedia https://infobatik.id/sejarah-batik-majalengka/

D’Ambrosio, U. (1985). Ethnomathematics and its Place in the History and Pedagogy of Mathematics. For the Learning of Mathematics, 1(February), 44-47.

Richardo, R. (2017). Peran Ethnomatematika Dalam Penerapan Pembelajaran Matematika Pada Kurikulum 2013. LITERASI (Jurnal Ilmu Pendidikan), $7(2), \quad 118$. https://doi.org/10.21927/literasi.2016.7(2).118-125

Prahmana, R.C.I., Zulkardi, Y. H. (2012). Learning Multiplication Using Indonesian Traditional game in Third Grade. Journal on Mathematics Education, 3(2), 32.

Shanty, N. O. (2016). Investigating St Udents ' Development of Learning. Journal on Mathematics 
Education, 7(2), 57-72.

Spencer-Oatey, H. (2012). What is Culture? A compilation of quotation. GlobalPAD Open House, 2. http://go.warwick.ac.uk/globalpadintercultural

Tampomas, H. (2008). Seribu Pena Matematika Kelas XII. Jakarta : Erlangga

Zayyadi, M. (2017). Eksplorasi Etnomatematika Pada Batik Madura. Sigma, 2(2), 35-40. 